\title{
Guideline update for the performance of fusion procedures for degenerative disease of the lumbar spine. Part 12: Pedicle screw fixation as an adjunct to posterolateral fusion
}

\author{
Michael W. Groff, M.D., ${ }^{1}$ Andrew T. Dailey, M.D., ${ }^{2}$ Zoher Ghogawala, M.D., ${ }^{3}$ \\ DaNiel K. RESNiCK, M.D. ${ }^{4}$ William C. WATters III, M.D. ${ }^{5}$ \\ Praveen V. Mummaneni, M.D., ${ }^{6}$ Tanvir F. Choudhri, M.D., ${ }^{7}$ Jason C. Eck, D.O., M.S., ${ }^{8}$ \\ Alok Sharan, M.D., ${ }^{9}$ Jeffrey C. Wang, M.D., ${ }^{10}$ SanJay S. Dhall, M.D., ${ }^{6}$ \\ ANd Michael G. KaISER, M.D. ${ }^{11}$ \\ ${ }^{1}$ Department of Neurosurgery, Brigham and Women's Hospital, Boston, Massachusetts; ${ }^{2}$ Department of \\ Neurosurgery, University of Utah, Salt Lake City, Utah; ${ }^{3}$ Alan and Jacqueline Stuart Spine Research Center, \\ Department of Neurosurgery, Lahey Clinic, Burlington, and Tufts University School of Medicine, Boston, \\ Massachusetts; ${ }^{4}$ Department of Neurosurgery, University of Wisconsin, Madison, Wisconsin; ${ }^{5}$ Bone and \\ Joint Clinic of Houston, Houston, Texas; ${ }^{6}$ Department of Neurological Surgery, University of California, \\ San Francisco, California; ${ }^{7}$ Department of Neurosurgery, Icahn School of Medicine at Mount Sinai, New \\ York, New York; ${ }^{8}$ Center for Sports Medicine and Orthopaedics, Chattanooga, Tennessee; ${ }^{9}$ Department of \\ Orthopaedic Surgery, Montefiore Medical Center, Albert Einstein College of Medicine, Bronx, New York; \\ ${ }^{10}$ Department of Orthopaedic Surgery, Keck School of Medicine, University of Southern California, Los \\ Angeles, California; and "Department of Neurosurgery, Columbia University, New York, New York
}

\begin{abstract}
The utilization of pedicle screw fixation as an adjunct to posterolateral lumbar fusion (PLF) has become routine, but demonstration of a definitive benefit remains problematic. The medical evidence indicates that the addition of pedicle screw fixation to PLF increases fusion rates when assessed with dynamic radiographs. More recent evidence, since publication of the 2005 Lumbar Fusion Guidelines, suggests a stronger association between radiographic fusion and clinical outcome, although, even now, no clear correlation has been demonstrated. Although several reports suggest that clinical outcomes are improved with the addition of pedicle screw fixation, there are conflicting findings from similarly classified evidence. Furthermore, the largest contemporary, randomized, controlled study on this topic failed to demonstrate a significant clinical benefit with the use of pedicle screw fixation in patients undergoing PLF for chronic low-back pain. This absence of proof should not, however, be interpreted as proof of absence. Several limitations continue to compromise these investigations. For example, in the majority of studies the sample size is insufficient to detect small increments in clinical outcome that may be observed with pedicle screw fixation. Therefore, no definitive statement regarding the efficacy of pedicle screw fixation as a means to improve functional outcomes in patients undergoing PLF for chronic low-back pain can be made. There appears to be consistent evidence suggesting that pedicle screw fixation increases the costs and complication rate of PLF. High-risk patients, including (but not limited to) patients who smoke, patients who are undergoing revision surgery, or patients who suffer from medical conditions that may compromise fusion potential, may appreciate a greater benefit with supplemental pedicle screw fixation. It is recommended, therefore, that the use of pedicle screw fixation as a supplement to PLF be reserved for those patients in whom there is an increased risk of nonunion when treated with only PLF. (http://thejns.org/doi/abs/10.3171/2014.4.SPINE14277)
\end{abstract}

$\begin{array}{lllll}\text { KEY WoRds } & \bullet \quad \text { lumbar spine } \\ \text { adjunct } & \text { practice guidelines }\end{array}$

\section{Recommendations}

There is no evidence that conflicts with the previous recommendations published in the original version of the "Guidelines for the performance of fusion procedures for degenerative disease of the lumbar spine."

\footnotetext{
Abbreviations used in this paper: $\mathrm{DPQ}=$ Dallas Pain Questionnaire; JOA = Japanese Orthopaedic Association; PLF = posterolateral lumbar fusion; SF-36 = 36-Item Short Form Health Survey.
}

\section{Grade B}

Pedicle screw fixation is recommended when posterolateral lumbar fusion (PLF) is used to manage lowback pain in patients at high risk for pseudarthrosis.

Routine use of pedicle screw fixation as an adjunct to PLF for patients with degenerative disc disease is an option. There is consistent evidence that the use of pedicle screws enhances the fusion rate; however, a positive correlation with respect to clinical outcome has not been consistently demonstrated. 


\section{Rationale}

Arthrodesis of the lumbar spine has become an accepted treatment option for spinal disorders manifesting with low-back pain. Although there is an ever-increasing collection of techniques to achieve a successful arthrodesis, the traditional PLF remains a commonly performed and successful surgical approach. The inclusion of internal fixation through pedicle screw stabilization has become a routine addition to PLF. Pedicle screw fixation as an adjunct to PLF is known to have advantages, including a higher fusion rate, and disadvantages, including higher cost and a higher rate of complications. The purpose of this update is to review the current medical literature and determine if the evidence supports or refutes the role for pedicle screws as an adjunct of PLF in the treatment of degenerative spinal disorders, such as low-grade degenerative spondylolisthesis, leading to low-back pain.

\section{Search Criteria}

A computerized search of the National Library of Medicine database of the literature published from July 2003 to December 2011 was performed using the following search terms: ((("Lumbosacral Region”[MeSH] OR "Lumbar Vertebrae"[MeSH]) AND "Spinal Fusion" [MeSH]) OR "lumbar fusion"[All Fields] OR ("lumbar" [title] AND "fusion"[title])) AND ("low back pain"[MeSH] OR("low"[AllFields]AND "back"[AllFields]AND“pain" [All Fields]) OR "low back pain"[All Fields]) AND ("Bone Screws"[MeSH] OR "pedicle screw*"[All Fields] AND ((“2003”[PDAT]: “3000”[PDAT]) AND "humans"[MeSH] AND English[lang])) AND ("humans" [MeSH] AND English[lang] AND ("aged"'[MeSH] OR "aged, 80 and over" [MeSH])). The search was limited to clinical series reported in English-language journals dealing with adult patients who had fusion with instrumentation for degenerative lumbar disease and yielded 258 publications. Among the articles reviewed, references were included if they described a comparison of fusion techniques with or without instrumentation. These references are summarized in Table 1.

\section{Scientific Foundation}

There is a wealth of literature demonstrating the positive impact of pedicle screw fixation on fusion rates in patients treated with PLF. Although a small number of papers report an improvement in functional outcomes with pedicle screw fixation, the quality of these data is low from an evidence-based medicine perspective. ${ }^{9,13}$ The results of the articles reviewed indicates that pedicle screw fixation for degenerative spondylosis has little if any impact on functional outcome..$^{5,6,9,11}$ This conclusion served as the basis for the recommendations of the previous Lumbar Fusion Guidelines. ${ }^{10}$ Since our original review there have been several well-designed studies that address the utility of pedicle screw fixation in the context of degenerative disc disease of the lumbar spine.

Korsgaard et al. performed a randomized prospective study evaluating the impact of pedicle screws with respect to clinical outcome in 130 patients undergoing treatment of degenerative lumbar disease. ${ }^{8}$ All patients underwent PLF and were randomly assigned to either a noninstrumented or instrumented cohort. Fusion status was assessed using the Christensen classification, which utilizes static anteroposterior and lateral radiographs. ${ }^{3}$ Clinical outcomes were evaluated using the Dallas Pain Questionnaire (DPQ). There were no significant differences between the treatment cohorts with respect to baseline demographic characteristics. At 2 years after surgery, no significant difference was observed between the 2 groups with respect to fusion rate or clinical outcome. Bjarke Christensen et al. reevaluated this same group of patients 5 years after surgery and found no significant difference in functional outcome; however, the authors did observe a higher reoperation rate in the instrumented group $(25 \%$ vs $14 \%$ in the noninstrumented group). ${ }^{2}$ It should be recognized, however, that only $11 \%$ of the reoperations in the instrumented group were for complications associated with the hardware. A subgroup analysis demonstrated that patients with "primary degenerative instability" experienced a greater improvement on the DPQ with instrumentation as compared with the noninstrumented cohort.

Andersen et al. performed a prospective nonrandomized study evaluating the role of pedicle screw fixation in patients over 60 years of age undergoing a posterolateral fusion with fresh-frozen allograft for degenerative lumbar spondylosis. ${ }^{1}$ Pedicle screw stabilization was performed at the discretion of the operating surgeon. The authors used allograft in an attempt to avoid the morbidity associated with harvesting iliac crest autograft. The indications for a fusion included preoperative or anticipated iatrogenic instability, as well as significant back pain before surgery. Clinical outcome was assessed with the DPQ. Fusion status was assessed with static plain radiographs. All outcome measures were improved with instrumentation compared with noninstrumented fusion. The fusion rate was higher in the instrumented group ( $81 \%$ vs $68 \%$ ). It should be remembered that the study was not randomized and the mean age of the patients in the instrumented group was lower than the mean age of the patients in the noninstrumented group.

Several case series have also provided evidence regarding PLF for degenerative lumbar spondylosis. ${ }^{7}$ Epstein investigated the outcome in 75 cases involving geriatric patients who underwent noninstrumented lumbar fusion with local autograft and a beta-tricalcium phosphate graft extender. ${ }^{4}$ Clinical outcome was assessed with the 36-Item Short Form Health Survey (SF-36), and fusion was assessed with CT scans and flexion-extension radiographs. In this study, Epstein documented a fusion rate of $83 \%$ and an improvement in all aspects of the SF-36, with the exception of mental health, which remained unchanged.

Tsutsumimoto et al. performed a retrospective analysis of a series of 42 cases involving patients who underwent noninstrumented PLF for degenerative lumbar stenosis. ${ }^{12}$ Fusion status was assessed with flexion-extension radiographs, and clinical outcome was measured with the Japanese Orthopaedic Association (JOA) scale. The fusion rate was $74 \%$. At 5 years postsurgery there was a significant improvement in the JOA scores of the patients in whom fusion was achieved when compared with those who had 
Part 12: Pedicle screw fixation as an adjunct to PLF

TABLE 1: Pedicle screw fixation as an adjunct to PLF: summary of evidence*

\begin{tabular}{|c|c|c|c|}
\hline Authors \& Year & $\begin{array}{l}\text { Level of } \\
\text { Evidence }\end{array}$ & Brief Description & Comments \\
\hline $\begin{array}{l}\text { Korsgaard et al., } \\
2002\end{array}$ & II & $\begin{array}{l}\text { Prospective randomized study of } 130 \text { pts w/ degenerative lumbar spondylosis. Pts } \\
\text { underwent PLF w/ or w/o PS fixation. Follow-up } 2 \text { yrs. DPQ used for outcome } \\
\text { assessment. Lumbar lordosis \& fusion determined by plain radiographs. There } \\
\text { was no significant btwn-groups difference on DPQ. No correlation btwn lordosis \& } \\
\text { DPQ. Fusion rate similar w/ or w/o PS fixation. }\end{array}$ & $\begin{array}{l}\text { No power calculation. Static } \\
\text { radiographs used for fu- } \\
\text { sion analysis. Nonstan- } \\
\text { dard, divergent method of } \\
\text { sacral screw insertion. }\end{array}$ \\
\hline $\begin{array}{l}\text { Andersen et al., } \\
2009\end{array}$ & III & $\begin{array}{l}\text { Prospective cohort study of } 94 \text { pts older than } 60 \text { yrs of age who underwent PLF w/ } \\
\text { allograft. No instrumentation was used in } 51 \text { cases; PS fixation was used in } 43 \text {. } \\
\text { Outcome was assessed using DPQ, LBPRS, \& SF-36. Fusion was assessed } \\
\text { using plain radiographs. Pts were followed for 2-7 yrs. Pts treated w/ PS fixation } \\
\text { had superior outcome (mean follow-up } 4.3 \text { yrs). }\end{array}$ & $\begin{array}{l}\text { Downgraded to Level III } \\
\text { because fusion was as- } \\
\text { sessed w/ static radio- } \\
\text { graphs \& the follow-up rate } \\
\text { was } 76 \% \text {. }\end{array}$ \\
\hline Jäger et al., 2003 & III & $\begin{array}{l}\text { Prospective cohort study of } 33 \text { pts. All underwent PLF; instrumentation was used in } \\
17 \text { cases. Indication for surgery defined only as degenerative instability. Fusion } \\
\text { was assessed w/ standard radiographs. Flexion-extension or CT was used only if } \\
\text { needed. ODI was used. No difference reported in fusion or clinical outcomes. Pt } \\
\text { accrual required } 11 \text { yrs, creating potential for substantial bias. }\end{array}$ & $\begin{array}{l}\text { Limitations included small } \\
\text { sample size \& lack of vali- } \\
\text { dated standard for evaluat- } \\
\text { ing radiographic evidence } \\
\text { of fusion. Downgraded to } \\
\text { Level III evidence. }\end{array}$ \\
\hline $\begin{array}{l}\text { Bjarke Christensen } \\
\quad \text { et al., } 2002\end{array}$ & $\|$ & $\begin{array}{l}\text { Prospective randomized study of } 129 \text { pts w/ chronic low-back pain. Pts were treated } \\
\text { w/ PLF w/ or w/o PS fixation \& followed for } 5 \text { yrs ( } 93 \% \text { follow-up). DPQ \& LBPRS } \\
\text { were used. For the entire cohort there were no statistically significant differences } \\
\text { in functional outcome or fusion rates. Fusion was assessed w/ static radiographs. } \\
\text { Subgroup analysis demonstrated that pts } w / \text { isthmic spondylolisthesis had } \\
\text { improved outcomes w/ noninstrumented PLF while pts w/ primary degenerative } \\
\text { instability had better outcomes w/ instrumented PLF. }\end{array}$ & $\begin{array}{l}\text { Block randomization, w/ power } \\
\text { analysis. Static radiographs } \\
\text { used for fusion analysis. } \\
\text { Unclear if a standardized } \\
\text { surgical technique utilized. } \\
\text { LBPRS was not adminis- } \\
\text { tered prior to surgery. }\end{array}$ \\
\hline $\begin{array}{l}\text { Fischgrund et al., } \\
1997\end{array}$ & II & $\begin{array}{l}\text { Prospective randomized study of } 76 \text { pts w/ spondylolisthesis \& spinal stenosis. Pts } \\
\text { were randomized to PLF w/ or w/o PS fixation. Fusion rate was higher in instru- } \\
\text { mented group ( } 82 \% \text { vs } 45 \% \text { ), while outcome was superior in noninstrumented } \\
\text { group ( } 85 \% \text { vs } 76 \% \text { ). }\end{array}$ & $\begin{array}{l}\text { Small sample size \& nonvali- } \\
\text { dated outcome \& fusion } \\
\text { measures. Follow-up } 88 \% \\
\text { at } 2 \text { yrs. }\end{array}$ \\
\hline Fritzell et al., 2002 & II & $\begin{array}{l}\text { Prospective randomized study of } 222 \text { pts randomized to PLF, PLF + PS fixation, \& } \\
\text { PLF + PS + IBF. Follow-up } 91 \% \text { at } 2 \text { yrs. All groups improved equally on VAS \& } \\
\text { ODI. Complication rates were } 6 \%, 16 \%, \& 31 \% \text {. }\end{array}$ & $\begin{array}{l}\text { No power calculation. Under- } \\
\text { powered. }\end{array}$ \\
\hline Lorenz et al., 1991 & ॥ & $\begin{array}{l}\text { Prospective randomized study of } 68 \text { pts w/ disabling back pain. Pts were random- } \\
\text { ized to PLF or PLF + PS fixation. Follow-up at mean } 26 \text { mos w/ flexion-extension } \\
\text { radiographs \& RTW. Fusion rate, pain score, \& RTW superior w/ PS fixation. }\end{array}$ & $\begin{array}{l}\text { RTW \& pain score. Lack } \\
\text { of validated outcome } \\
\text { measure. }\end{array}$ \\
\hline Zdeblick, 1993 & II & $\begin{array}{l}\text { Prospective, randomized study of } 124 \text { pts: PLF, PLF + semi-rigid PS fixation, PLF + } \\
\text { PS. Fusion determined w/ flexion-extension radiographs at } 1 \mathrm{yr}: 65 \%, 77 \%, 95 \% \text {. }\end{array}$ & $\begin{array}{l}\text { Clinical outcome measure } \\
\text { not validated. }\end{array}$ \\
\hline
\end{tabular}

* DPQ = Dallas Pain Questionnaire; IBF = interbody fusion; LBPRS = Low Back Pain Rating Scale; ODI = Oswestry Disability Index; PLF = posterolateral lumbar fusion; PS = pedicle screw; pt = patient; RTW = return to work; SF-36 = 36-Item Short Form Health Survey; VAS = visual analog scale.

pseudarthrosis (3.5 vs 2.5). Regression analysis revealed that fusion status and comorbidity were the strongest predictors of the improvement demonstrated on the JOA scale.

\section{Summary}

The role of pedicle screw stabilization as an adjunct to PLF for lumbar degenerative disease continues to be an area of intense investigation. In the years since the original guideline publication, new evidence has been generated, demonstrating that the improved fusion rate with the use of pedicle screws can lead to improved clinical outcomes (Level II) and that pseudarthrosis is associated with worse long-term clinical outcome (Level IV). An improved fusion rate with the application of pedicle screw stabilization has been well established from previous published reports. Although the recent literature is more suggestive of a relationship between successful fusion and improved clinical outcomes, a direct clinical benefit for the use of pedicle screws still has not been conclusively established. We therefore recommend that pedicle screws be used routinely as an adjunct to PLF for low-back pain only in cases that pose an increased risk for pseudarthrosis. Those cases include, but are not limited to, those involving patients who smoke, present with kyphotic deformity, or suffer systemic diseases associated with poor bone healing. The use of pedicle screw fixation in other cases is associated with an increase in the fusion rate, but any association with improved outcome is less well defined. 


\section{Key Issues for Future Investigation}

There is convincing support in the literature for the beneficial impact of pedicle screw fixation on arthrodesis. There is also support for the beneficial impact of a successful arthrodesis on clinical outcome. Nonetheless, studies examining the impact of pedicle screw fixation on clinical outcome have been inconclusive. Further investigation should elucidate the cause of this apparent contradiction. Possible explanations include the complication profile of pedicle screw insertion and the multifactorial aspect of clinical outcomes in this challenging patient population.

\section{Acknowledgments}

We would like to acknowledge the AANS/CNS Joint Guidelines Committee (JGC) for their review, comments, and suggestions; Laura Mitchell, CNS Guidelines Project Manager, for her organizational assistance; and Linda O'Dwyer, medical librarian, for assistance with the literature searches. We would also like to acknowledge the following individual JGC members for their contributions throughout the review process: Timothy Ryken, M.D.; Kevin Cockroft, M.D.; Sepideh Amin-Hanjani, M.D.; Steven N. Kalkanis, M.D.; John O’Toole, M.D., M.S.; Steven Casha, M.D., Ph.D.; Aaron Filler, M.D., Ph.D., F.R.C.S.; Daniel Hoh, M.D.; Steven Hwang, M.D.; Todd McCall, M.D.; Jeffrey J. Olson, M.D.; Julie Pilitsis, M.D., Ph.D.; Joshua Rosenow, M.D.; and Christopher Winfree, M.D.

\section{Disclosure}

Administrative costs of this project were funded by the Congress of Neurological Surgeons and the Joint Section on Disorders of the Spine and Peripheral Nerves of the American Association of Neurological Surgeons and Congress of Neurological Surgeons. No author received payment or honorarium for time devoted to this project. Dr. Ghogawala receives grants from the Patient Centered Outcomes Research Institute (PCORI) and the National Institutes of Health (NIH). Dr. Groff is a consultant for DePuy Spine and EBI Spine. Dr. Mummaneni owns stock in Spinicity and receives honoraria from DePuy Spine and Globus and royalties from DePuy Spine, Quality Medical Publishers, and Thieme Publishing. Dr. Wang owns stock in Bone Biologics, AxioMed, Amedica, CoreSpine, Expanding Orthopedics, Pioneer, Syndicom, VG Innovations, PearlDiver, Flexuspine, Axis, FzioMed, Benvenue, Promethean, Nexgen, ElectroCore, and Surgitech and holds patents with and receives royalties from Biomet, Stryker, SeaSpine, Aesculap, Osprey, Amedica, Synthes, and Alphatec. The authors report no other potential conflicts of interest concerning the materials or methods used in this study or the findings specified in this paper.

Author contributions to the study and manuscript preparation include the following. Acquisition of data: all authors. Analysis and interpretation of data: all authors. Drafting the article: Groff. Critically revising the article: all authors. Reviewed submitted version of manuscript: all authors. Approved the final version of the manuscript on behalf of all authors: Groff. Study supervision: Kaiser.

\section{References}

1. Andersen T, Christensen FB, Niedermann B, Helmig P, Høy $\mathrm{K}$, Hansen ES, et al: Impact of instrumentation in lumbar spinal fusion in elderly patients: 71 patients followed for 2-7 years. Acta Orthop 80:445-450, 2009

2. Bjarke Christensen F, Stender Hansen E, Laursen M, Thom- sen K, Bünger CE: Long-term functional outcome of pedicle screw instrumentation as a support for posterolateral spinal fusion: randomized clinical study with a 5-year follow-up. Spine (Phila Pa 1976) 27:1269-1277, 2002

3. Christensen FB, Laursen M, Gelineck J, Eiskjaer SP, Thomsen $\mathrm{K}$, Bunger CE: Interobserver and intraobserver agreement of radiograph interpretation with and without pedicle screw implants: the need for a detailed classification system in posterolateral spinal fusion. Spine (Phila Pa 1976) 26:538-544, 2001

4. Epstein NE: An analysis of noninstrumented posterolateral lumbar fusions performed in predominantly geriatric patients using lamina autograft and beta tricalcium phosphate. Spine J 8:882-887, 2008

5. Fischgrund JS, Mackay M, Herkowitz HN, Brower R, Montgomery DM, Kurz LT: 1997 Volvo Award Winner in Clinical Studies. Degenerative lumbar spondylolisthesis with spinal stenosis: a prospective, randomized study comparing decompressive laminectomy and arthrodesis with and without spinal instrumentation. Spine (Phila Pa 1976) 22:2807-2812, 1997

6. Fritzell P, Hägg O, Wessberg P, Nordwall A, Swedish Lumbar Spine Study Group: Chronic low back pain and fusion: a comparison of three surgical techniques: a prospective multicenter randomized study from the Swedish Lumbar Spine Study Group. Spine (Phila Pa 1976) 27:1131-1141, 2002

7. Jäger M, Seller K, Raab P, Krauspe R, Wild A: Clinical outcome in monosegmental fusion of degenerative lumbar instabilities: instrumented versus non-instrumented. Med Sci Monit 9:CR324-CR327, 2003

8. Korsgaard M, Christensen FB, Thomsen K, Hansen ES, Bünger C: The influence of lumbar lordosis on spinal fusion and functional outcome after posterolateral spinal fusion with and without pedicle screw instrumentation. J Spinal Disord Tech 15:187-192, 2002

9. Lorenz M, Zindrick M, Schwaegler P, Vrbos L, Collatz MA, Behal R, et al: A comparison of single-level fusions with and without hardware. Spine (Phila Pa 1976) 16 (8 Suppl):S455S458, 1991

10. Resnick DK, Choudhri TF, Dailey AT, Groff MW, Khoo L, Matz PG, et al: Guidelines for the performance of fusion procedures for degenerative disease of the lumbar spine. Part 12: pedicle screw fixation as an adjunct to posterolateral fusion for low-back pain. J Neurosurg Spine 2:700-706, 2005

11. Thomsen K, Christensen FB, Eiskjaer SP, Hansen ES, Fruensgaard S, Bünger CE: 1997 Volvo Award Winner in Clinical Studies. The effect of pedicle screw instrumentation on functional outcome and fusion rates in posterolateral lumbar spinal fusion: a prospective, randomized clinical study. Spine (Phila Pa 1976) 22:2813-2822, 1997

12. Tsutsumimoto T, Shimogata M, Yoshimura Y, Misawa H: Union versus nonunion after posterolateral lumbar fusion: a comparison of long-term surgical outcomes in patients with degenerative lumbar spondylolisthesis. Eur Spine J 17:11071112,2008

13. Zdeblick TA: A prospective, randomized study of lumbar fusion. Preliminary results. Spine (Phila Pa 1976) 18:983-991, 1993

Manuscript submitted March 13, 2014.

Accepted April 8, 2014.

Please include this information when citing this paper: DOI: 10.3171/2014.4.SPINE14277.

Address correspondence to: Michael G. Kaiser, M.D., Columbia University, Neurological Surgery, The Neurological Institute, 710 W. 168th St., New York, NY 10032. email:mgk7@columbia.edu. 